\title{
ERODIBILIDADE DE UM CAMBISSOLO HÚMICO ALUMÍNICO LÉPTICO, DETERMINADA SOB CHUVA NATURAL ENTRE 1989 E 1998 EM LAGES (SC) ${ }^{(1)}$
}

\author{
I. BERTOL (2), J . SCHICK(3), O. BATISTELA(4), \\ D. LEITE ${ }^{(4)} \&$ A. J . AMARAL ${ }^{(4)}$
}

\begin{abstract}
RESUMO
O fator de erodi bilidade do solo (fator K) da Equação Universal de Perda de Solo (EUPS) refere-se à susceptibilidade natural do solo à erosão e representa a quanti dade de solo perdida por unidade de erosi vidade da chuva (fator $\mathbf{R}$ ), sendo o seu conhecimento importante no planejamento conservacionista. Utilizando dados de perda de solo, obtidos sob condições de chuva natural, em tanques coletores de escoamento superficial, e de erosi vidade $\left(\mathrm{E} \mathrm{I}_{30}\right)$ das chuvas naturais, no período de 1989 a 1998, em Lages (SC), calculou-se, pelo quociente entre essas variáveis e por regressão linear simples entre elas, o fator de erodibilidade do solo para um Cambissolo Húmico alumínico léptico com $0,102 \mathrm{~m} \mathrm{~m}^{-1} \mathrm{de}$ declividade média. Com este objetivo, foram utilizados valores de erosividade $\left(\mathrm{EI}_{30}\right.$ ) de 437 eventos de chuva e de perdas de solo, obtidas em parcelas de $3,5 \times 22,1 \mathrm{~m}$ desprovidas de vegetação e crosta superficial. O preparo do solo, executado no sentido paralelo ao declive duas vezes ao ano, consistiu de uma aração e duas gradagens. Os valores de erodibilidade médios anuais, estimados pelo quociente e por regressão linear simples entre as perdas de solo e as erosividades, foram de 0,0115 e $0,0151 \mathrm{Mg}$ ha h ha-1 $\mathrm{MJ}^{-1} \mathrm{~mm}^{-1}$, respectivamente. Pelos respectivos modos de obtenção, os valores de erodibilidade médios estacionais estimados foram de 0,0105 e 0,0121 Mg ha h ha-1 $\mathrm{MJ} \mathrm{J}^{-1} \mathrm{~mm}^{-1}$, para a

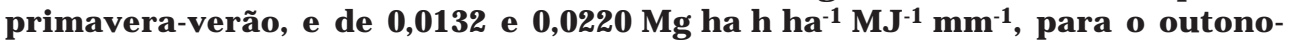
inverno.
\end{abstract}

Termos de indexação: fator K, erosão hídrica, perda de solo, EUPS.

\footnotetext{
(1) Parte da Tese de Mestrado do segundo autor, executado com recursos da UDESC e CNPq, apresentada na II RNRS/SBCS, Santa Maria (RS). Recebido para publicação em janeiro de 2001 e aprovado em outubro de 2001.

(2) Professor do Departamento de Sol os do Centro de Ciências Agroveterinárias, Universidade do Estado de Santa Catarina - UDESC. Caixa Postal 281, CEP 88520-000 Lages (SC). Bolsista do CNPq. Email: a2ib@cav.udesc.br

(3) Engenheiro-Agrônomo, MSc., CAV/UDESC.

(4) Bolsista de I niciação Científica do Curso de Agronomia do CAV/UDESC.
} 


\title{
SUMMARY: ERODIBILITY IN INCEPTISOL, DETERMINED UNDER NATURAL RAINFALL BETWEEN 1989 AND 1998 IN LAGES, SANTA CATARINA STATE, BRAZIL
}

\begin{abstract}
Thesoil erodibility factor ( $K$ factor) of theU niversal Soil Loss Equation (USLE) refers to the natural soil susceptibility to erosion and represents the quantity of lost soil per rain erosivity unit ( $R$ factor), a factor, which is of great importancein conservation management. Using data of soil loss, measured under natural rainfall conditions in collector ponds of superficial runoff, and of natural rainfall erosivity $\left(\mathrm{EI}_{30}\right)$ in the period from 1989 to 1998 in Lages (SC), thesoi I erodi bility factor for a I ncepti sol was cal culated with an averageincline/ gradient of $0.102 \mathrm{~m} \mathrm{~m}^{-1}$ by thequotient and simplel inear regressi on between thesevariables. With this objective, erosivity values $\left(\mathrm{EI}_{30}\right.$ ) of 437 rainfalls and soil loss wereused, measured in $3.5 \times 22.1 \mathrm{~m}$ plots, without vegetation or superficial covering. Soil preparation, carried out twice a year paralle to the incline/ gradient, consisted in ploughing/ tillage and two discings. Annual averageerodi bility values, estimated by thequotient and by simplelinear regression between soil loss and erosivity, were 0.0115 and $0.0151 \mathrm{Mg}$ ha h ha-1 $\mathrm{MJ}^{-1} \mathrm{~mm}^{-1}$, respectively. The estimated average seasonal erodibility values were 0.0105 and $0.0121 \mathrm{Mg}$ ha h ha-1 $\mathrm{MJ}^{-1} \mathrm{~mm}^{-1}$ for spring/ summer and 0.0132 and $0.0220 \mathrm{Mg}^{2} \mathrm{~h} \mathrm{ha-1} \mathrm{MJ}^{-1}$ $\mathrm{mm}^{-1}$ for fall/ winter, according to the respective ways of measurement.
\end{abstract}

Index terms: Factor K, water/ hydro-erosion, soil loss, USLE.

\section{NTRODUÇÃO}

A erosão hídrica é o resultado da ação da chuva e escoamento superficial sobre o solo, caracterizada pel as fases de desagregação, transporte e deposição. A desagregação e o transporte são principalmente provocados pelo impacto das gotas de chuva e pelo escoamento superficial, respectivamente, sobre a superfície do solo (Hudson, 1981).

A erodibilidade (fator $K$ da EUPS) significa a susceptibilidade do solo à erosão hídrica, sendo expressa como a quantidade de solo perdida por unidade de erosividade (fator R da EUPS) (Wischmeier \& Smith, 1978). A erodibilidade pode ser cal culada por meio do quociente entre as perdas de solo e as erosividades das chuvas (Wischmeier, 1958; Wischmeier \& Smith, 1978), ou, ainda, prevista por meio de regressão linear simples entre as erosividades das chuvas e suas respectivas perdas de solo (Wischmeier \& Mannering, 1969).

A referida regressão é expressa pelo modelo $Y=a+b X$, em queY representa as perdas de sol o e $X$, as erosividades das chuvas. Neste caso, a erodi bilidade do solo é representada pela incl inação da reta, b, respeitado o grau de confiabilidade do coeficiente de regressão, $r^{2}$, quando os dados são obtidos ou ajustados para as condições da parcelapadrão da Equação Universal de Perda de Solo (EUPS), proposta por Wischmeier \& Smith (1958) e Wischmeier \& Smith (1978).

A erodibilidade do solo apresenta grande variabilidade espacial e temporal, explicada pela diversidade climática, a qual influi no potencial erosivo das chuvas, e variabilidade de solo, a qual tem influência na susceptibilidade à erosão. Foster et al. (1981) sugeriram os valores de 0,010, 0,030 e $0,060 \mathrm{Mg}$ ha h ha-1 $\mathrm{MJ}^{-1} \mathrm{~mm}^{-1}$, para classificar a erodibilidade dos solos americanos como baixa, moderada e alta, respectivamente.

A erodibilidade de um Latossolo Vermelho distrófico típico, determinada por Denardin \& Wunsche (1980), em Passo Fundo (RS), foi de $0,021 \mathrm{Mg}$ ha h ha-1 $\mathrm{MJ}^{-1} \mathrm{~mm}^{-1}$. Num solo de mesma classe, determinada por Dedecek et al. (1986), em Planaltina (DF), epor Martins Filho \& Pereira (1993), em J aboticabal (SP), a erodibilidade foi de 0,013 e $0,009 \mathrm{Mg}$ ha h ha-1 $\mathrm{MJ}^{-1} \mathrm{~mm}^{-1}$, respectivamente. Bertol (1994) eSchick (1999), trabal hando com dados de três e seis anos, obtiveram, respectivamente, os valores de 0,016 e 0,013 $\mathrm{Mg}$ ha h ha-1 $\mathrm{MJ}^{-1} \mathrm{~mm}^{-1}$, para a erodibilidade de um Cambissolo Húmico alumínicoléptico em Lages (SC), enquanto Marques et al. (1997) obtiveram os valores de 0,002 e $0,033 \mathrm{Mg}$ ha h ha-1 $\mathrm{MJ}^{-1} \mathrm{~mm}^{-1}$, para um Latossolo Vermel ho distrófico típico e um Argissolo VermelhoAmarelo alumínico típico, respectivamente, de Sete Lagoas (MG). J acobs et al. (1994) obtiveram valores de erodibilidade de 0,0084 e 0,0086 $\mathrm{Mg}$ ha h ha-1 MJ ${ }^{-1} \mathrm{~mm}^{-1}$, utilizando as equações de energia cinética propostas por Wischmeier \& Smith (1958) eWagner \& Massambani (1988), respectivamente, para um L atossolo Vermelho-E scuro textura média, de Paranavaí (PR), e para um Latossolo Vermelho distrófico típico, de Ponta Grossa (PR), os val ores de 0,0086 e 0,0086 $\mathrm{Mg}$ ha h ha-1 $\mathrm{MJ}^{-1} \mathrm{~mm}^{-1}$, utilizando, respectivamente, as equações anteriormente referidas. Beutler (2000), trabalhando num Latossolo Vermelho aluminoférrico típico de Chapecó, SC, obteve o valor de erodibilidade de $0,0212 \mathrm{Mg}$ ha h ha-1 $\mathrm{MJ}^{-1} \mathrm{~mm}^{-1}$. 
O objetivo do presente trabalho foi determinar o fator erodibilidade de um Cambissolo Húmico alumínico léptico, sob condições de chuva natural, bem como sua variação estacional, na região de Lages (SC), no período de 1989 a 1998.

\section{MATERIAL E MÉTODOS}

A pesquisa foi desenvol vida no Centro de Ciências Agroveterinárias (CAV/UDESC) de Lages (SC), no período de 1989 a 1998, com um intervalo de um ano (1992), no qual não foram coletados dados de perda de solo do experimento. Os dados de chuva foram obtidos na Estação Meteorológica do Centro de Ciências Agroveterinárias de Lages (SC), situada a $27^{\circ} 49^{\prime}$ latitude Sul e $50^{\circ} 20^{\prime}$ longitude Oeste de Grenwich. A altitude média de Lages é de $953 \mathrm{~m}$, com temperaturas, máxima e mínima, médias anuais de 21,7 e $11,5^{\circ} \mathrm{C}$, respectivamente. Segundo Köepen, o clima da região é do tipo $\mathrm{Cfb}$.

A erodibilidade foi determinada com base em dados de perda de solo obtidos em experimento realizado sob chuva natural, num Cambissolo Húmico alumínico léptico, local izado no Campus do Centro de Ciências Agroveterinárias de Lages (SC), com declividade média de $0,102 \mathrm{~m} \mathrm{~m}^{-1}$ nas parcelas experimentais.

$\mathrm{Na}$ camada de $0-20 \mathrm{~cm}$ de profundidade, o solo apresentava $421 \mathrm{~g} \mathrm{~kg}^{-1}$ de argila, $437 \mathrm{~g} \mathrm{~kg}^{-1}$ de silte e $142 \mathrm{~g} \mathrm{~kg}^{-1}$ de areia, densidade do solo de $1,28 \mathrm{~kg} \mathrm{dm}^{-3}$ e densidade de partículas de $2,69 \mathrm{~kg} \mathrm{dm}^{-3}$, volumes de microporos $0,38 \mathrm{dm}^{3} \mathrm{dm}^{-3}$, macroporos de $0,09 \mathrm{dm}^{3} \mathrm{dm}^{-3}$ e total de poros de $0,47 \mathrm{dm}^{3} \mathrm{dm}^{-3}$. Na mesma profundidade, o teor de carbono orgânico era de $3,96 \mathrm{~g} \mathrm{~kg}^{-1}$, $\mathrm{P}$ extraível 2,40 $\mathrm{mg} \mathrm{kg}^{-1} \mathrm{eK}, \mathrm{Ca}+\mathrm{Mg}$ eAl trocáveis, 2,87, 1,01 e $0,02 \mathrm{mmol}_{\mathrm{C}} \mathrm{kg}^{-1}$, respectivamente, e $\mathrm{pH}$ em água (1:1), 5,6.

A taxa constante de infiltração de água no solo, determinada pelo método dos cilindros concêntricos, era de $6,2 \mathrm{~mm} \mathrm{~h}^{-1}$ quando da instalação do experimento, em 1988. Foram instaladas parcelas de 3,5 x 22,1 m, em duas repetições, delimitadas por chapas gal vanizadas, nas laterais ena extremidade superior, e por calhas coletoras de enxurrada, na extremidade inferior, conectadas por canos de PVC aos tanques coletores com divisores de vazão, localizados $6,0 \mathrm{~m}$ abaixo da parcela experimental. A col eta e a quantificação da erosão foram feitas a cada evento de chuva erosiva, conforme o método descrito em Cogo (1978).

Durante o experimento, as parcelas foram preparadas duas vezes por ano, com uma aração e duas gradagens no sentido paral el o ao decl ive: uma vez antecedendo a cultura de primavera-verão e, outra, a de outono-inverno. O solo das parcelas foi mantido livre de vegetação e crosta superficial durante o período experimental, por meio de dessecantes químicos e capinas ou escarificações manuais.

O fator de erodibilidade médio anual foi determinado utilizando 339 dados de perdas de solo, resultantes de 437 chuvas erosivas, selecionadas segundo o critério deWischmeier (1959). O referido fator foi calculado por meio do quociente entre a perda de sol o média anual ( $\left.\mathrm{Mg} \mathrm{ha}^{-1}\right)$ e a erosividade média anual das chuvas ( $\mathrm{MJ} \mathrm{mm} \mathrm{ha}^{-1} \mathrm{~h}^{-1}$ ), seguindo o procedimento deWischmeier \& Smith (1978), bem como por análise de regressão linear simples entre os valores das referidas variáveis, seguindo o procedimento de Wischmeier \& Mannering (1969), sendo expresso em $\mathrm{Mg}$ ha $\mathrm{h}$ ha-1 $\mathrm{MJ}^{-1} \mathrm{~mm}^{-1}$.

Assim, dentre as 437 chuvas erosivas, várias delas, em alguns eventos, foram acumuladas, resultando em 339 coletas de solo. A erodibilidade do solo foi determinada, ainda, para o período de primavera-verão, com 179 dados de perdas de solo, resultantes de 215 chuvas erosivas e, para o período de outono-inverno, com 166 dados de perdas desolo, resultantes de 222 chuvas erosivas, por meio dos dois métodos supramencionados.

Os dados de perda de sol o foram ajustados para a declividade-padrão da EUPS, ou seja, 0,09 $\mathrm{m} \mathrm{m}^{-1}$, por meio do fator grau de declive, conforme proposto por Wischmeier \& Smith (1978), utilizando a equação:

$$
\mathrm{S}=0,065+4,56 \operatorname{sen} \theta+65,41(\operatorname{sen} \theta)^{2}
$$

em que

$$
\begin{aligned}
& S=\text { fator grau do declive (adimensional) e } \\
& \theta=\text { ângulo do declive (adimensional). }
\end{aligned}
$$

O fator deerosividade $\left(\mathrm{EI}_{30}\right)$ foi calculado conforme Wischmeier (1959) e Wischmeier \& Smith (1978), utilizando o método proposto por Foster et al. (1981).

\section{RESULTADOS E DISCUSSÃO}

O fator de erodibilidade médio anual, obtido pelo quociente entre as perdas de solo e as erosividades das chuvas, variou amplamente no período estudado (Quadro 1). O menor valor ocorreu em 1991 e o maior em 1990, com uma diferença de aproximadamente 15 vezes, embora a erosividade tenha sido apenas 1,6 vez mai or em 1990, provocando, no entanto, uma perda de solo aproximadamente 24 vezes maior nesse ano. Tal comportamento é explicado, provavel mente, pela mel hor distribuição das chuvas em 1991, com maior espaçamento entre elas e, conseqüentemente, menor teor de umidade do solo antecedente à maioria das referidas chuvas. Assim, as chuvas em 1991, menos erosivas, produziram menor erosão hídrica também porque preci pitaram sobre o sol o provavel mente mais seco. 
Quadro 1. Valores médios anuais do fator erosividade - $\mathrm{EI}_{30}$ (fator $\mathrm{R}$ ) das chuvas, perda de solo (média de duas repetições) e fator erodibilidade (fator $\mathrm{K}$ ) determinados pelo quociente entre a média das perdas de solo e a média das erosividades das chuvas, do Cambissolo Húmico alumínico léptico em Lages (SC), no período de 1989 a 1998

\begin{tabular}{cccc}
\hline Ano & Fator R - E I $\mathbf{3 0}$ & Perda de solo & Fator K \\
\hline & MJ mm ha-1 $\mathrm{h}^{-1}$ & Mg ha-1 & Mg ha h ha-1 $\mathrm{MJ}^{-1} \mathrm{~mm}^{-1}$ \\
1989 & 4.458 & 44,10 & 0,0099 \\
1990 & 7.539 & 146,97 & 0,0195 \\
1991 & 4.610 & 6,17 & 0,0013 \\
1993 & 5.157 & 59,82 & 0,0116 \\
1994 & 5.546 & 40,42 & 0,0073 \\
1995 & 2.990 & 4,89 & 0,0016 \\
1996 & 6.655 & 72,83 & 0,0109 \\
1997 & 8.031 & 84,78 & 0,0106 \\
1998 & 7.120 & 138,26 & 0,0194 \\
Média & 5.790 & 66,47 & 0,0115 \\
C.V. (\%) & 27 & 72 & 54 \\
\hline
\end{tabular}

Quadro 2. Valores médios estacionais do fator erosividade - $\mathrm{EI}_{30}$ (fator $\mathrm{R}$ ) das chuvas, perda de solo (média de duas repeti ções) e fator erodibilidade (fator K) deter minados pelo quociente entre a média das perdas de solo e a média das erosividades das chuvas, do Cambissolo Húmico alumínico léptico em Lages (SC), na primavera-verão de 1989 a 1998

\begin{tabular}{cccc}
\hline Ano & Fator $\mathbf{R}-\mathbf{E I}_{\mathbf{3 0}}$ & Perda de solo & Fator K \\
\hline & MJ mm ha-1 $\mathrm{h}^{-1}$ & $\mathrm{Mg} \mathrm{ha-1}$ & Mg ha h ha-1 $\mathrm{MJ}^{-1} \mathrm{~mm}^{-1}$ \\
1989 & 3.086 & 41,13 & 0,0133 \\
1990 & 3.629 & 5,47 & 0,0015 \\
1991 & 3.089 & 4,13 & 0,0013 \\
1993 & 2.354 & 3,24 & 0,0014 \\
1994 & 4.338 & 37,34 & 0,0086 \\
1995 & 1.719 & 2,82 & 0,0016 \\
1996 & 5.236 & 67,44 & 0,0129 \\
1997 & 4.725 & 73,49 & 0,0156 \\
1998 & 4.886 & 111,82 & 0,0229 \\
Média & 3.674 & 38,54 & 0,0105 \\
C.V. (\%) & 31 & 96 & 73 \\
\hline
\end{tabular}

A variação temporal das perdas médias anuais de solo foi expressivamente maior do que das erosividades das chuvas, refletindo-se parcial mente na erodibilidade do sol o (Quadro 1). O valor médio anual do fator $\mathrm{K}$ foi de $0,0115 \mathrm{Mg}$ ha $\mathrm{h} \mathrm{ha}^{-1} \mathrm{MJ}{ }^{-1} \mathrm{~mm}^{-1}$; em 1989, 1993, 1996 e 1997, os valores do fator K foram semel hantes aos da média anual, enquanto, nos demais anos, o fator $\mathrm{K}$ foi diferente do valor médio anual. Esteval or de erodibilidade indica que cada unidade de erosividade ocasionou uma perda média anual de solo de $0,0115 \mathrm{Mg} \mathrm{ha}^{-1}$, diferindo levementedos valores encontrados por Bertol (1994) e Schick (1999) para o mesmo solo, sendo diferente, ainda, dos fatores de erodi bilidade encontrados por outros autores, para solos distintos (Denardin \& Wunshe, 1980; Martins Filho \& Pereira, 1993; J acobs et al., 1994; Marques et al., 1997; Beutler, 2000), obtidos do mesmo modo.

O valor médio de erodibilidade do solo na primavera-verão, obtido pelo quociente entre as perdas de solo e as erosividades das chuvas, foi de $0,0105 \mathrm{Mg}$ ha h ha-1 $\mathrm{MJ}^{-1} \mathrm{~mm}^{-1}$ (Quadro 2), cerca de $9 \%$ menor do que o valor médio anual $\left(0,0115 \mathrm{Mg}\right.$ ha h ha-1 $\mathrm{MJ}^{-1} \mathrm{~mm}^{-1}-$ Quadro 1$)$. Nesse 
período, a menor erodibilidade também ocorreu em 1991, cujo val or foi 88\% menor do que a média dessa estação do ano, enquanto a maior erodibilidade ocorreu em 1998, com um valor 2,2 vezes maior do que a referida média. Tanto a mai or quanto a menor erodibilidade média estacional, ocorridas nesses dois anos, foram mais influenciadas pelas perdas de solo do que pelas erosividades, pois, enquanto a erodibilidade variou cerca de 18 vezes entre o maior e o menor val or, a perda de sol o variou 27 vezes e a erosividade, 1,6 vez do mai or valor, ocorrido em 1998, para o menor, em 1991.

A expressiva variação das perdas de solo na primavera-verão (Quadro 2) mostra, ainda, queelas foram fortementeinfluenciadas, provavel mente, pela umi dade do solo antecedenteàs chuvas e pela desuniformidade de sua distribuição ao longo do período experimental. Nesse período, apenas os valores anuais de erodibilidade de 1989, 1996 e 1997 foram relativamente semel hantes ao val or médio estacional e, dentreos demais, apenas oano de 1998 apresentou valor expressivamente mai or do que a média.

No outono-inverno, a erodibilidade média (Quadro 3), obtida pelo quociente entre as perdas de solo e as erosividades das chuvas, foi de $0,0132 \mathrm{Mg}$ ha h ha-1 $\mathrm{MJ}^{-1} \mathrm{~mm}^{-1}$, ou seja, cerca de $15 \%$ mai or do que o valor médio anual (Quadro 1 ). Isto ocorreu porque a erosividade média desse período foi equival entea apenas $37 \%$ da erosividade média anual, enquanto a perda média de solo da referida estação equivaleu a $42 \%$ da média anual, ou seja, nesse período, cada unidade de erosividade produziu perda de solo maior do que aquela que proporcionou a média anual. Cada unidade de erosividade provocou uma perda de solo cerca de $26 \%$ mai or no outono-inverno (Quadro 3) do que na primavera-verão (Quadro 2). I Isto indica que, no outono-inverno, a resistência natural do solo à erosão foi menor do que na primavera-verão, graças, provavelmente, à umidade, a qual condiciona parcialmente a consistência do solo e, conseqüentemente, a sua resistência à erosão hídrica.

$\mathrm{O}$ maior valor do fator $\mathrm{K}$ no outono-inverno ocorreu em 1990, o qual foi cerca de 28 vezes maior do que o menor val or, ocorrido em 1991 (Quadro 3). Isto é explicado princi palmente pela diferença nas perdas de solo, que foram de aproximadamente 69 vezes, enquanto a erosividade variou apenas 2,6 vezes.

Foi relativamentegrande a dispersão dos pontos relativos aos valores médios anuais de erosividade e de perda de solo (Figura 1a), o que pode ser comprovado pelo baixo valor do coeficiente de regressão $\left(r^{2}=0,30\right)$, concordando com dados obtidos por Bertol (1994), Schick (1999) e Beutler (2000). A distribuição dos pontos mostra que a variação foi ampla, tanto para baixos quanto para altos valores de erosividade. Isso pode ser parcial mente explicado pel ocurto período de tempo e relativamente reduzido número de eventos estudados, mostrando que algumas chuvas, de alta erosividade, ocasionaram baixas perdas de solo, enquanto outras, de baixa erosividade, produziram altas perdas de solo. Tal ocorrência deveu-se, provavel mente, à variabilidade do teor de umidade antecedente do solo por ocasião das chuvas.

No entanto, foram mais comuns chuvas de baixa erosividade produzirem altas perdas de solo do que chuvas dealta erosividade produzirem baixas perdas desolo, indicando que, na média anual, possivel mente, a umidade do solo esteve alta por um período de tempo mais longo, favorecendo a ação das chuvas

Quadro 3. Valores médios estacionais do fator erosividade - $\mathrm{EI}_{30}$ (fator $\mathbf{R}$ ) das chuvas, perda de solo (média de duas repetições) e fator erodibilidade (fator $\mathrm{K}$ ) determinados pelo quociente entre as médi as das perdas de solo e as médias das erosi vidades das chuvas, do Cambi ssolo Húmico alumínico léptico em Lages (SC), no outono-inverno de 1989 a 1998

\begin{tabular}{cccc}
\hline Ano & Fator $\mathbf{R}-\mathbf{E I}_{\mathbf{3} \mathbf{0}}$ & Perda de solo & Fator K \\
\hline & MJ mm ha-1 $\mathrm{h}^{-1}$ & Mg ha-1 & Mg ha h ha-1 $\mathrm{MJ}^{-1} \mathrm{~mm}^{-1}$ \\
1989 & 1.372 & 2,97 & 0,0022 \\
1990 & 3.910 & 141,50 & 0,0362 \\
1991 & 1.521 & 2,04 & 0,0013 \\
1993 & 2.803 & 56,59 & 0,0202 \\
1994 & 1.208 & 3,07 & 0,0025 \\
1995 & 1.271 & 2,07 & 0,0016 \\
1996 & 1.419 & 5,39 & 0,0038 \\
1997 & 3.306 & 11,29 & 0,0034 \\
1998 & 2.234 & 26,43 & 0,0118 \\
Média & 2.116 & 27,93 & 0,0132 \\
C.V. (\%) & 45 & 156 & 90 \\
\hline
\end{tabular}


erosivas. O val or da erodibilidade, nesse caso, foi de $0,0151 \mathrm{Mg}$ ha h ha-1 $\mathrm{MJ}^{-1} \mathrm{~mm}^{-1}$, como indicado pelo coeficiente de determinação, o qual representa a variação nas perdas de sol o por unidade de variação na erosividade. Este valor do fator $K$ foi praticamente igual ao encontrado por Bertol (1994) para o mesmo solo e mesmo modo de obtenção, diferindo, no entanto, dos val ores obtidos, para outros solos, por vários autores (Denardin \& Wunshe, 1980; Martins Filho \& Pereira, 1993; J acobs et al., 1994; Marques et al., 1997; Beutler, 2000), cujos valores foram obtidos pel o quociente entre perdas de sol o e erosividades.

A variabilidade dos dados de perda de sol o com a variação das erosividades foi menor, quando se analisaram apenas os dados da primavera-verão (Figura $1 b$ ) do que quando foram considerados os dados médios anuais (Figura $1 \mathrm{la}$ ), conforme demonstra o maior coeficiente de regressão $\left(r^{2}=0,48\right)$. Na primavera-verão, houve melhor equivalência entre as erosividades das chuvas e as perdas de solo, indicando que, em geral, chuvas de alta erosividade ocasionaram altas perdas de sol o e chuvas de baixa erosividade ocasionaram baixas perdas de solo. A erodibilidade, nesse caso, foi de $0,0121 \mathrm{Mg}$ ha h ha-1 $\mathrm{MJ}^{-1} \mathrm{~mm}^{-1}$, como indicado pelo coeficiente de determinação, ou seja, 20 \% inferior à dos dados médios anuais (Figura 1a).

No outono-inverno (Figura 1c), ocorreu maior variabilidade nas perdas de solo com a variação da erosividade do que na primavera-verão (Figura 1b). Algumas chuvas de erosividade rel ativamente baixa provocaram al tas perdas de sol o, enquanto a maioria das chuvas foi de baixa erosividadee provocou baixas perdas de solo, o que resultou numa maior dispersão dos dados na figura $1 c\left(r^{2}=0,44\right)$ do que na figura $1 b\left(r^{2}=0,48\right)$. Nesse caso, a erodibilidade foi de $0,0220 \mathrm{Mg}$ ha h ha-1 $\mathrm{MJ}^{-1} \mathrm{~mm}^{-1}$, ou seja, $46 \%$ maior do que quando foram considerados os dados médios anuais.

Os baixos valores $r^{2}$, originados pelas regressões que resultaram nos fatores de erodibilidade, indicam baixo grau de confiabilidade nos referidos fatores obtidos por esse método.

Comparando os valores de erodibilidade constantes nos quadros 1,2 e 3 com aqueles das figuras 1a, 1b e 1c, observa-se que, no caso dos dados médios anuais, a erodibilidade estimada por regressão linear simples (Figura 1a) foi $31 \%$ maior do que aquela estimada pelo quociente entre as perdas de solo e as erosividades (Quadro 1). Na primavera-verão, por outro lado, o valor do fator $\mathrm{K}$ obtido por regressão (Figura 1 b) foi cerca de $15 \%$ maior do aquele obtido pelo quociente entre perdas de solo e erosividades (Quadro 2), enquanto, no outono-inverno, o valor estimado por regressãolinear simples (Figura 1c) foi $67 \%$ maior do que aquele estimado pelo quociente entreas perdas de sol o eas erosividades (Quadro 3).
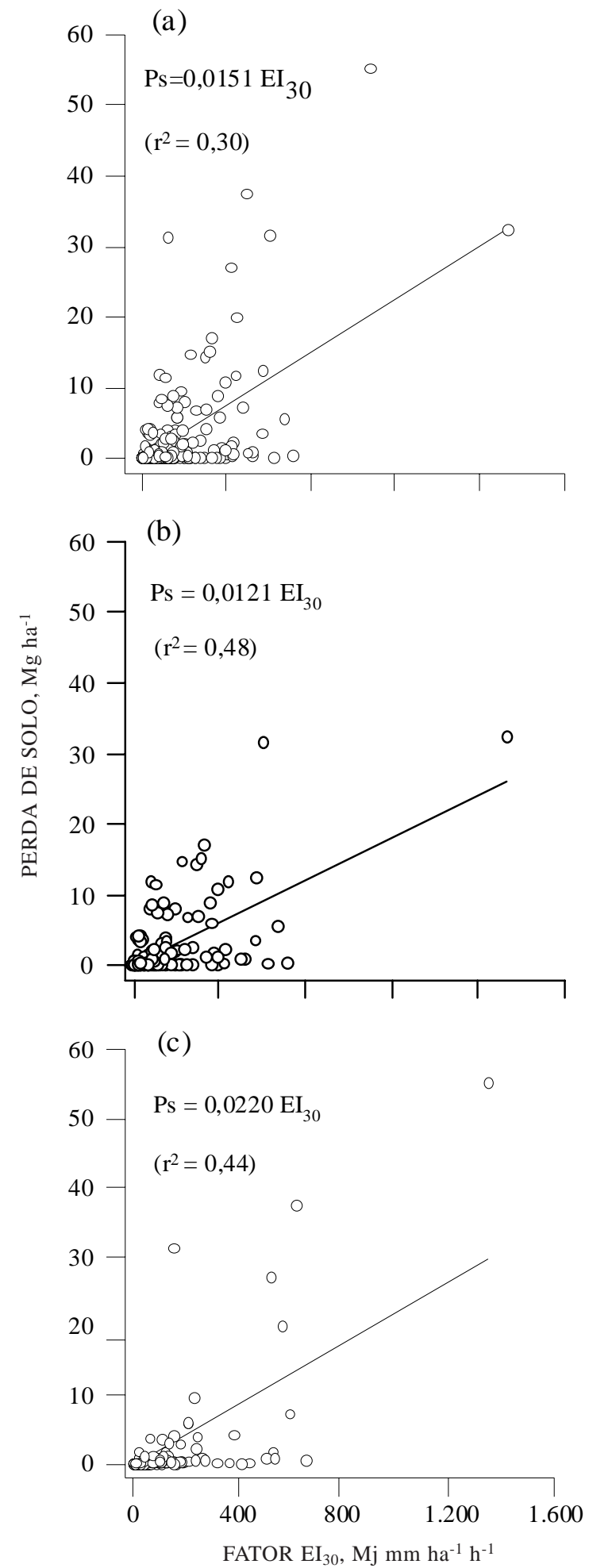

Figura 1. Relação do fator erosividade, $\mathrm{EI}_{30}$, com as perdas de solo, $\mathrm{Ps}$, (a) anual, com 437 eventos de erosividade e 339 dados de perda de solo; (b) primavera-verão, com 215 eventos de erosividade e 172 dados de perda de solo, e (c) outono-inverno, com 222 eventos de erosi vidade e 166 dados de perda de solo, para um Cambissolo Húmico alumínico léptico em Lages (SC), no período de 1989 a 1998. 
Diante do baixo grau de confiabilidade dos fatores deerodibilidade obtidos por regressãolinear simples, devem-se utilizar os valores dos referidos fatores obtidos pelo quociente entre as perdas de solo e as erosividades das chuvas.

\section{CONCLUSÃO}

1. O fator de erodibilidade médio anual do Cambissol o Húmico al umínico léptico, determinado pel o quociente entreas perdas médias anuais de solo e as erosividades médias anuais das chuvas, foi de $0,0115 \mathrm{Mg}$ ha h ha-1 $\mathrm{MJ}^{-1} \mathrm{~mm}^{-1}$.

2. Utilizando os dados da primavera-verão, o fator

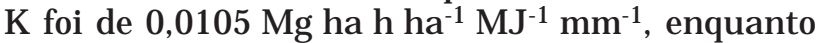
os dados de outono-inverno resultaram num fator $\mathrm{K}$ de $0,0132 \mathrm{Mg}$ ha h ha-1 $\mathrm{MJ}^{-1} \mathrm{~mm}^{-1}$.

3. O fator deerodi bilidade, determinado por regressão linear simples, foi de 0,0151 $\mathrm{Mg}$ ha $\mathrm{h} \mathrm{ha}^{-1} \mathrm{MJ}^{-1}$ $\mathrm{mm}^{-1}$, utilizando os dados médios anuais; de $0,0121 \mathrm{Mg}$ ha $\mathrm{h} \mathrm{ha}{ }^{-1} \mathrm{MJ}^{-1} \mathrm{~mm}^{-1}$, utilizando os dados

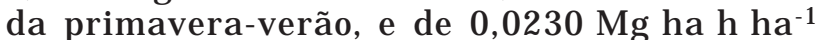
MJ ${ }^{-1} \mathrm{~mm}^{-1}$, utilizando os dados do outono-inverno.

\section{AGRADECIMENTO}

Aos acadêmicos do Curso de Agronomia do CAV/ UDESC, J armum Marcelos Massariol, É merson Fábio dos Reis e Leonir Dily, pelo auxílio na coleta dos dados no campo eseu tratamento no laboratório.

\section{LITE RATURA CITADA}

BERTOL, I. Erodibilidade de um Cambissolo Húmico distrófico determinada sob chuva natural: primeira aproximação. R. Bras. Ci. Solo, 18:335-338, 1994.

BEUTLER, J.F. Erosão hídrica num Latossolo Vermelho aluminoférrico submetido a diferentes sistemas de preparo e cultivo do solo. Lages, Universidade do Estado de Santa Catarina, 2000. 105p. (Tese de Mestrado)

COGO, N.P. U ma contribuição à metodologia de estudo das perdas por erosão em condições de chuva natural: I Sugestões gerais, medição do volume, amostragem e quantificação de solo da enxurrada (1a aproximação). In: ENCONTRO NACIONAL DE PESQUISA SOBRE CONSERVAÇÃO DO SOLO, 2., Passo Fundo, 1978. Anais. Passo F undo, Empresa Brasileira dePesquisa Agropecuária, 1978. p.57-98.
DEDECEK, R.A.; RESK, D.V.S. \& FREITAS J ÚNIOR, E. Perdas de solo, água e nutrientes por erosão em LatossoloVermel ho Escuro dos cerrados em diferentes cultivos sob chuva natural. R. Bras. Ci. Solo, 10:265-272, 1986.

DENARDIN, J.E. \& WUNSCHE, W.A. Erodibilidade de um Latossolo Vermel ho escuro. In: ENCONTRO NACIONAL DE PESQUISA SOBRE CONSERVAÇÃO DO SOLO, 3., Recife, 1981. Anais. Recife, Universidade Federal Rural de Pernambuco, 1980. p.219.

FOSTER, G.R.; MCCOOL, D.K.; RENARD, K.E. \& MOLDENHAUER, W.C. Conversion of the universal soil Ioss equation toSI metric units. Soil Water Conserv., 36:355359, 1981.

HUDSON, N.W. Soil conservation. 2.ed. Ithaca, Cornell University Press, 1981. 324p.

J ACOBS, G.A.; ROLOFF, G.; BISCAIA, R.C.M. \& MERTEN, G. Erosividade da chuva correlacionada com perdas de solo de dois Latossolos Vermelho-Escuros (texturas argilosa e média): uma aproximação do fator erodibilidade do solo. In: REUNIÃO BRASILEIRA DE MANEJO E CONSERVAÇÃO DO SOLO E DA ÁGUA, 10., Florianópolis, 1994. Resumos. Florianópolis, Sociedade Brasileira de Ciência do Solo, 1994. p.170-171.

MARTINS FILHO, M.V. \& PEREIRA, V.P. Influência da compactação do solo nas perdas por erosão e na sua erodibilidade. Ci. Agron., 8:39-45, 1993.

MARQUES, J.J.G.S.M.; ALVARENGA, R.C.; CURI, N.; SANTANA, D.P. \& SILVA, M.L.N. Índices de erosividade da chuva, perdas de solo e fator erodibilidade para dois solos da região dos cerrados - primeira aproximação. R. Bras. Ci. Solo, 21:427-434, 1997

SCHICK, J. Erosão hídrica em Cambissolo Húmico álico submetido a diferentes sistemas de preparo e cultivo do solo. Lages, Universidade do Estado de Santa Catarina, 1999. 114p. (Tese de Mestrado)

WAGNER, C.S. \& MASSAMBANI, O. Análise da relação intensidade da chuva-energia de Wischmeier \& Smith e sua aplicabilidade à região de São Paulo. R. Bras. Ci. Solo, 12:197-203, 1988.

WISCHMEIER, W.H. A rainfall erosion index for a universal soil loss equation. Soil Sci. Soc. Am. Proc., 23:246-249, 1958.

WISCHMEIER, W.H. \& MANNERING, J.V. Relation of soil properties to its erodibility. Proc. Soil Sci. Soc. Am., 33:131137, 1969

WISCHMEIER, W.H. \& SMITH, D.D. Rainfall energy and its relationship to soil loss. Trans. Am. Geophys. Union, 39:285-291, 1958.

WISCHMEIER, W.H. \& SMITH, D.D. Predicting rainfall erosion Iosses: a guide to conservation planning. Washington, United States Departament of Agriculture, 1978. 58p. (Agriculture Handbook, 537) 
I. BERTOL et al.

R. Bras. Ci. Solo, 26:465-471, 2002 